Supporting Information (SI) for

\title{
Nickel Nanoparticles Supported on Nitrogen-Doped Carbon for Vanillin Detection
}

Xue Nie ${ }^{\dagger, \neq}$, Peihong Deng $\neq$, Rui Zhang ${ }^{\dagger}$, Zheng Tang ${ }^{\dagger}$, Haiyan Wang ${ }^{\dagger}$, and Yougen Tang ${ }^{*}+$

†College of Chemistry and Chemical Engineering, Central South University, Changsha, 410083, P.R. China.

$¥$ Key Laboratory of Functional Metal-Organic Compounds of Hunan Province; Key Laboratory of Functional Organometallic Materials of Hunan Provincial Universities; College of Chemistry and Material Science, Hengyang Normal University, Hengyang, 421008, China.

"Correspondence: ygtang@csu.edu.cn; Tel.: +8607318830886; fax: +8607318879616 


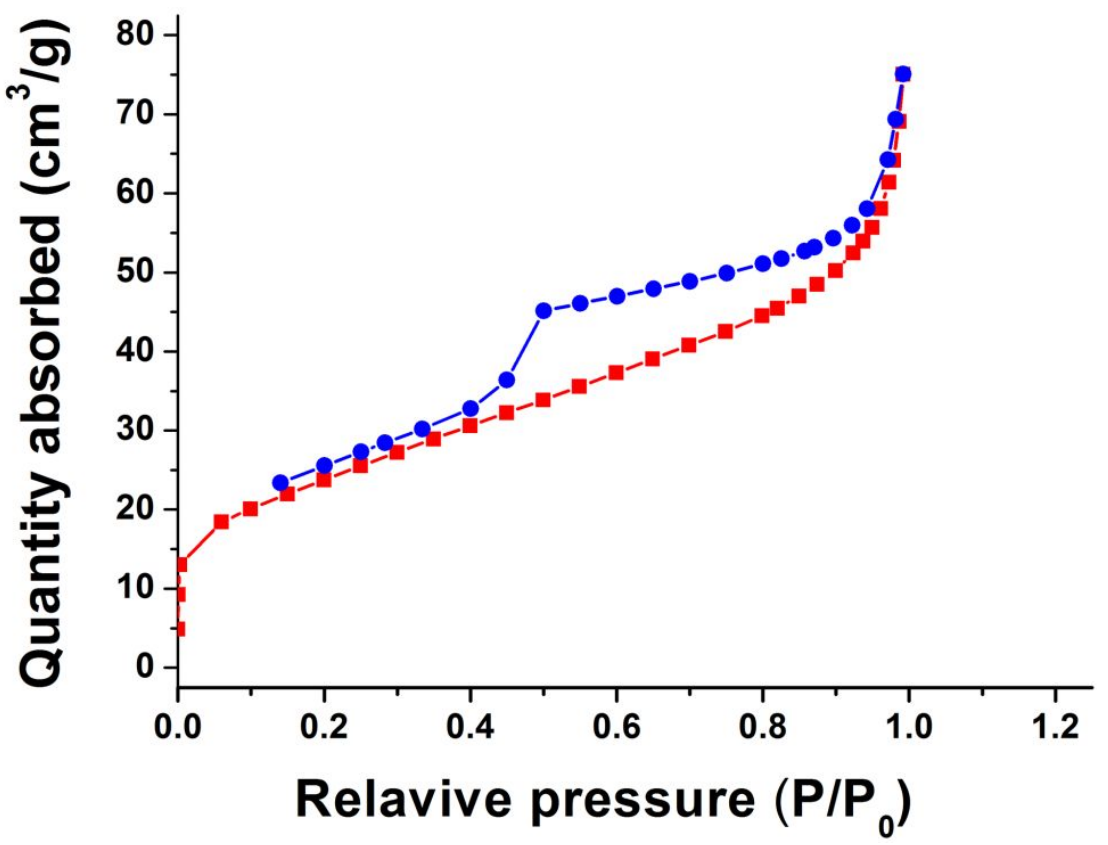

Figure S1. Nitrogen adsorption/desorption isotherms of the $\mathrm{Ni}$ NPs/N-C nanohybrid 


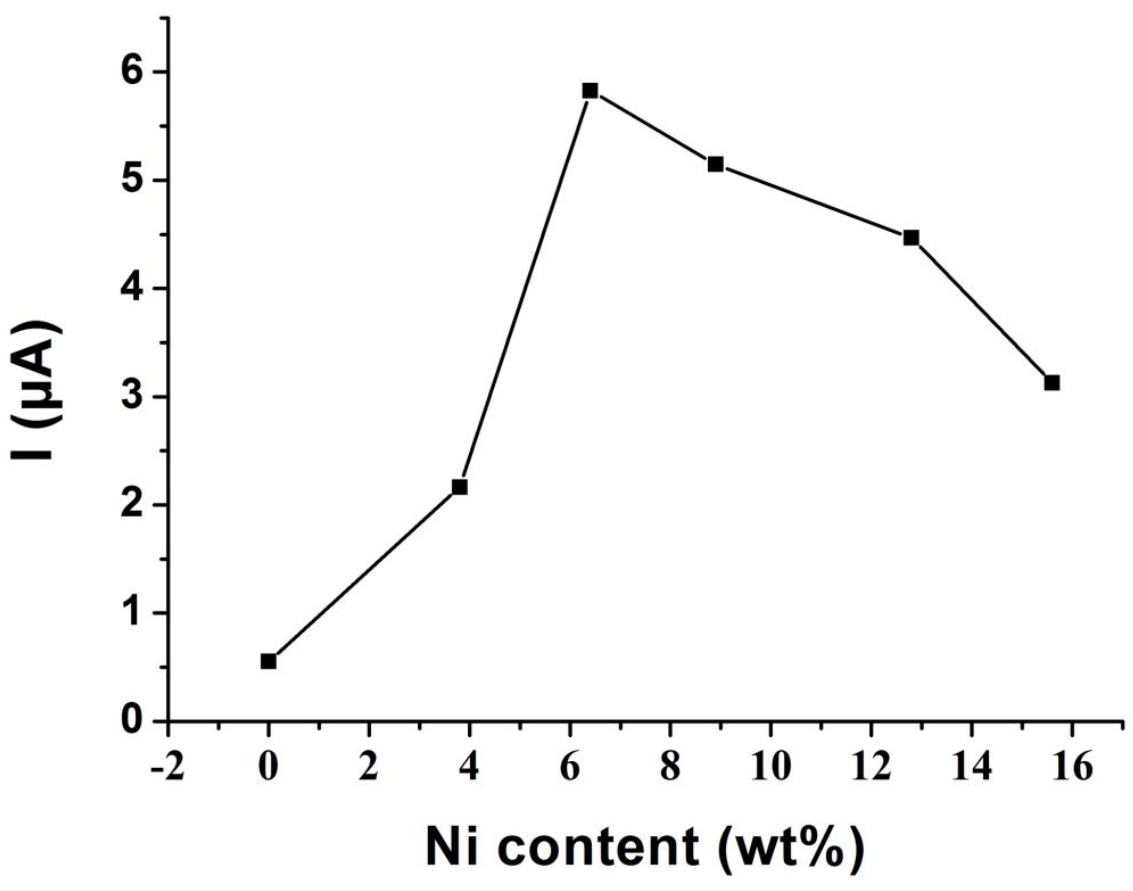

Figure S2. Effect of $\mathrm{Ni}$ content on the peak current of $10 \mu \mathrm{M}$ vanillin at the Ni NPs/N-C/CPE. 


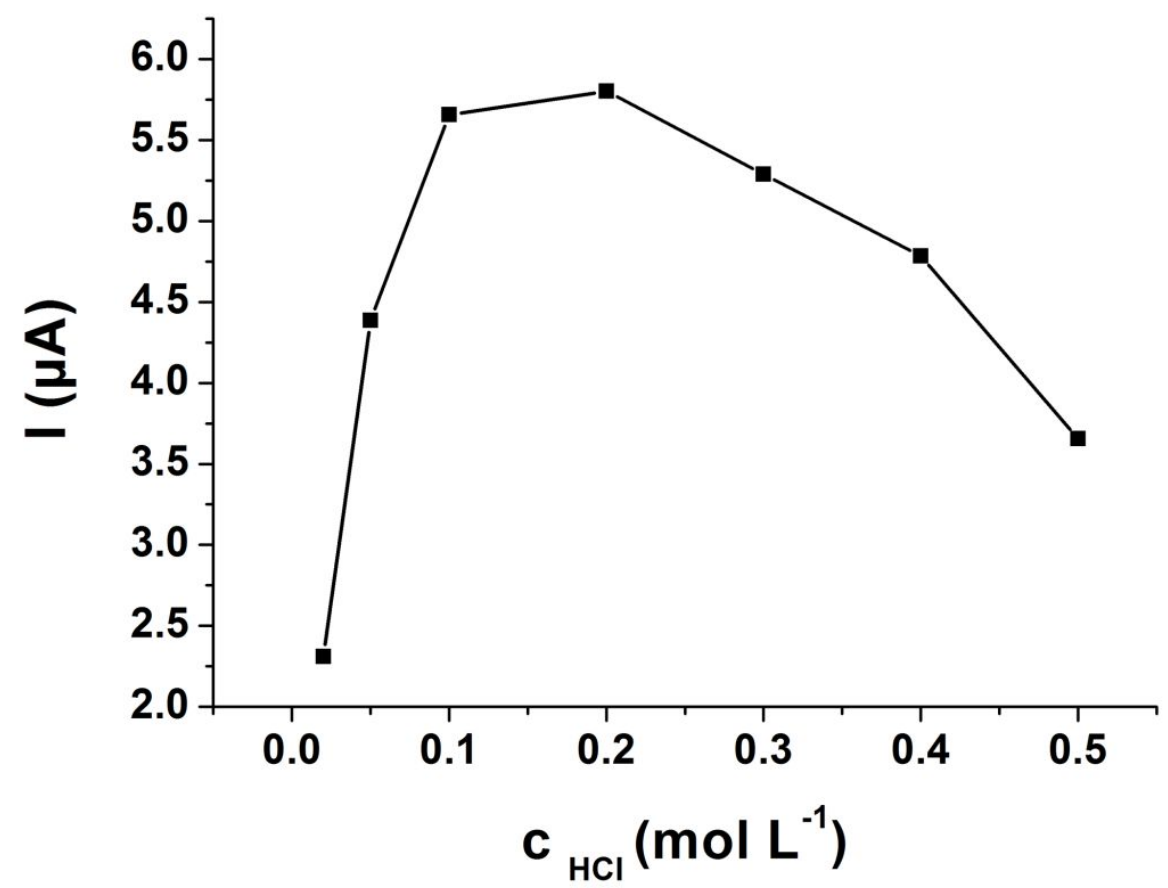

Figure S3. Effect of $\mathrm{HCl}$ concentration on the peak current of $10 \mu \mathrm{M}$ vanillin at $\mathrm{Ni} \mathrm{NPs/N-C/CPE.}$ 


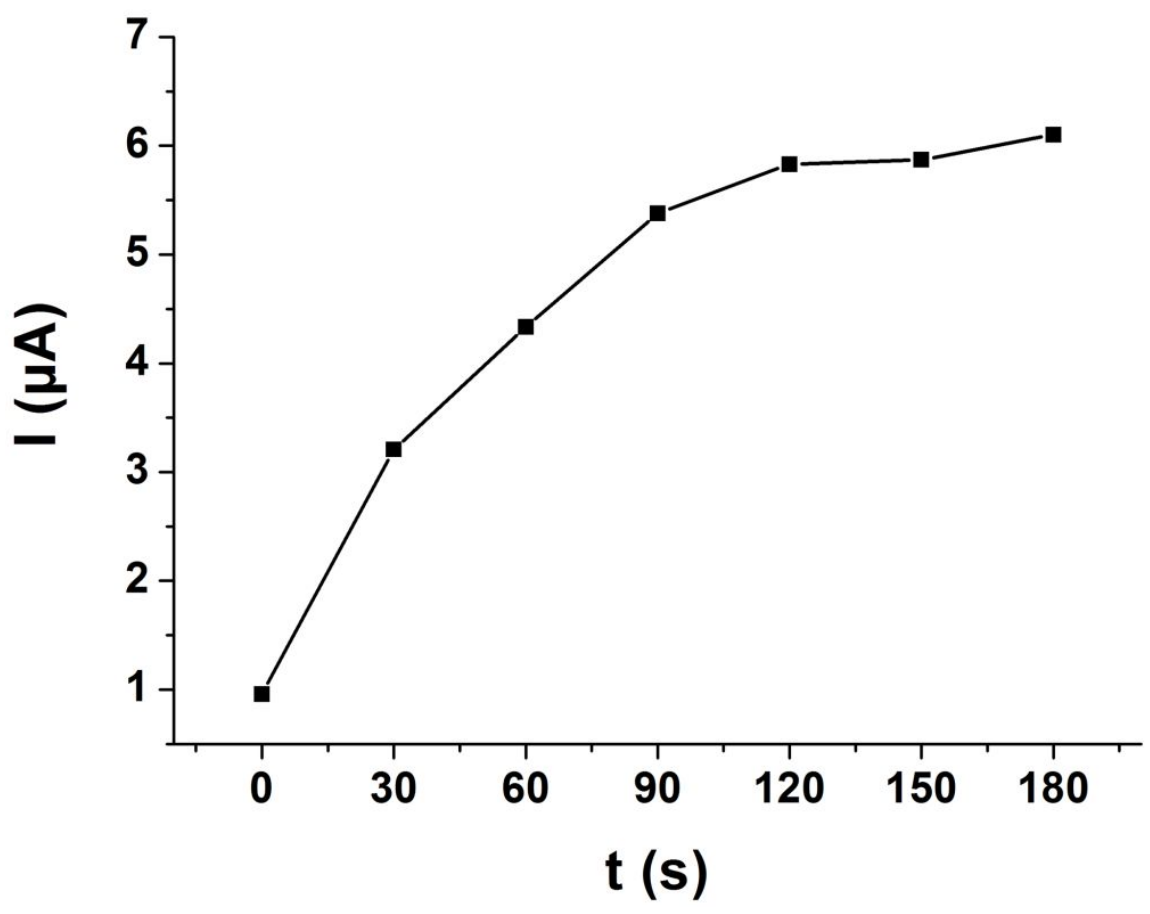

Figure S4. Effects of accumulation time on the oxidation peak currents of $10 \mu \mathrm{M}$ vanillin at Ni NPs/N-C/CPE. Scan rate: $0.1 \mathrm{~V} \mathrm{~s}^{-1}$. 
Table S1. The effect of different type of supporting electrolytes

(each $0.1 \mathrm{M}$ ) on the electrochemical response of $10 \mu \mathrm{M}$ vanillin

\begin{tabular}{ccc}
\hline supporting electrolytes & peak potential / $\mathrm{mV}$ & peak current/ $\mu \mathrm{A}$ \\
\hline $\mathrm{HCl}$ & 936 & 5.653 \\
$\mathrm{H}_{2} \mathrm{SO}_{4}$ & 944 & 3.895 \\
$\mathrm{HNO}_{3}$ & 948 & 5.157 \\
$\mathrm{H}_{3} \mathrm{PO}_{4}$ & 952 & 1.952 \\
$\mathrm{HAc}-\mathrm{NaAc}(\mathrm{pH} 4.0)$ & 828 & 1.451 \\
$\mathrm{HAc}-\mathrm{NH}_{4} \mathrm{Ac}(\mathrm{pH} 4.0)$ & 824 & 0.9813 \\
phosphate buffer $(\mathrm{pH} 6.0)$ & 795 & 0.5582 \\
\hline
\end{tabular}


Table S2. Influence of coexisting substances on the determination of $1.0 \mu \mathrm{M}$ vanillin

\begin{tabular}{|c|c|c|c|c|c|}
\hline $\begin{array}{l}\text { Coexisting } \\
\text { substance }\end{array}$ & $\begin{array}{l}\text { Concentration } \\
\qquad(\mathrm{mM})\end{array}$ & $\begin{array}{c}\text { Change of } \\
\text { peak current } \\
(\%)\end{array}$ & $\begin{array}{l}\text { Coexisting } \\
\text { substance }\end{array}$ & $\begin{array}{l}\text { Concentration } \\
\qquad(\mathrm{mM})\end{array}$ & $\begin{array}{c}\text { Change of } \\
\text { peak current } \\
(\%)\end{array}$ \\
\hline $\mathrm{K}^{+}$ & 0.5 & 1.38 & glucose & 0.5 & 2.54 \\
\hline $\mathrm{Ca}^{2+}$ & 0.5 & 1.25 & fructose & 0.5 & 1.62 \\
\hline $\mathrm{Na}^{+}$ & 0.5 & 1.54 & $\begin{array}{c}\text { ascorbic } \\
\text { acid }\end{array}$ & 0.5 & 3.17 \\
\hline $\mathrm{Zn}^{2+}$ & 0.5 & -0.68 & citric acid & 0.5 & -1.28 \\
\hline $\mathrm{Al}^{3+}$ & 0.5 & 2.14 & $\begin{array}{l}\text { tartaric } \\
\text { acid }\end{array}$ & 0.5 & 0.67 \\
\hline $\mathrm{Mg}^{2+}$ & 0.5 & -2.17 & lactic acid & 0.5 & 1.12 \\
\hline sucrose & 0.5 & 1.53 & caffeine & 0.5 & -2.14 \\
\hline
\end{tabular}


Table S3 Repeatability of Ni NPs/N-C/CPE

\begin{tabular}{cccccccc}
\hline $\begin{array}{c}\text { Determination } \\
\text { times }\end{array}$ & 1 & 2 & 3 & 4 & 5 & 6 & 7 \\
\hline Peak current $(\mu \mathrm{A})$ & 5.731 & 5.882 & 5.696 & 5.782 & 5.734 & 5.815 & 5.929 \\
$\begin{array}{c}\text { Relative standard } \\
\text { deviation (RSD) }\end{array}$ & & & & $1.47 \%$ & & & \\
\hline
\end{tabular}


Table S4 Reproducibility of Ni NPs/N-C/CPE

\begin{tabular}{cccccc}
\hline Electrode number & 1 & 2 & 3 & 4 & 5 \\
\hline Peak current $(\mu \mathrm{A})$ & 5.831 & 5.934 & 5.602 & 5.884 & 5.687 \\
$\begin{array}{c}\text { Relative standard } \\
\text { deviation (RSD) }\end{array}$ & & & $2.40 \%$ & & \\
\hline
\end{tabular}


Table S5 The storage stability of Ni NPs/N-C/CPE

\begin{tabular}{cccccccc}
\hline Days & 1 & 2 & 3 & 4 & 5 & 6 & 7 \\
\hline Peak current $(\mu \mathrm{A})$ & 5.815 & 5.824 & 5.820 & 5.813 & 5.804 & 5.719 & 5.618 \\
Days & 8 & 9 & 10 & 11 & 12 & 13 & 14 \\
Peak current $(\mu \mathrm{A})$ & 5.587 & 5.554 & 5.516 & 5.498 & 5.483 & 5.471 & 5.458 \\
\hline
\end{tabular}

